\title{
Psychometric properties of the Screen for Child Anxiety Related Emotional Disorders (SCARED) in the general Italian adolescent population: A validation and a comparison between Italy and The Netherlands
}

\author{
Elisabetta Crocetti ${ }^{\mathrm{a}, *}$, William W. Hale III $^{\mathrm{b}}$, Alessandra Fermani ${ }^{\mathrm{a}}$, \\ Quinten Raaijmakers ${ }^{\mathrm{b}}$, Wim Meeus ${ }^{\mathrm{b}}$

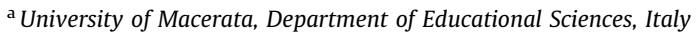 \\ ${ }^{\mathrm{b}}$ University of Utrecht, Research Centre Adolescent Development, The Netherlands
}

\section{A R T I C L E I N F O}

Article history:

Received 23 September 2008

Received in revised form 16 April 2009

Accepted 16 April 2009

\section{Keywords:}

Adolescents

Anxiety

SCARED

Validation

Cross-cultural

\begin{abstract}
A B S T R A C T
In this study examination is given to the psychometric properties of the Italian version of the Screen for Child Anxiety Related Emotional Disorders (SCARED) in a large community sample of adolescents. Additionally, a comparison was made between the anxiety scores of this Italian adolescent cohort $(N=1975)$ and a comparative Dutch adolescent cohort $(N=1115)$.

Findings revealed that a five-factor structure of the SCARED applied not only to the Italian adolescents from the general community, but also to boys and girls, and to early and middle adolescents. Moreover, sex and age differences on anxiety scores within the Italian sample were found to be consistent with previous studies of adolescent anxiety disorders. Finally, Italian adolescents reported higher anxiety scores than their Dutch peers.

Findings of this study highlight that the SCARED is a valid screening instrument to rate anxiety symptoms of Italian adolescents.
\end{abstract}

(c) 2009 Elsevier Ltd. All rights reserved.

\section{Introduction}

Anxiety is one of the most prevalent psychosocial problems among youth in Western societies (Ollendick, King, \& Muris, 2002). In epidemiological studies it has been reported that approximately $5-17 \%$ of children and adolescents suffer from an anxiety disorder (Bernstein, Borchardt, \& Perwien, 1996). It is crucial that anxiety symptoms are recognized since high levels of anxiety symptoms can hinder adolescent development (Crocetti, Klimstra, Keijsers, Hale, \& Meeus, in press) and anxiety symptoms many times have a chronic course that persists into adulthood (Roza, Hofstra, van der Hende, \& Verhulst, 2003).

Therefore, it is of utmost importance to have adequate tools to screen the severity of anxiety symptoms in the general adolescent population. Even though (semi-)structured interviews may be employed to evaluate DSM-IV-TR (DSM; American Psychiatric Association, 2000) anxiety disorders in adolescents, these interviews are highly time-consuming and require trained interviewers to be

\footnotetext{
* Corresponding author at: Department of Educational Sciences, University of Macerata, Postbox: Piazzale Luigi Bertelli (Contrada Vallebona) 62100, Macerata, Italy. Tel.: +390733 2585942; fax: +3907332585927.

E-mail address: elisabetta.crocetti@unimc.it (E. Crocetti).
}

administered. However, self-report questionnaires can be easily employed for screening purposes to ascertain whether adolescents fall within a high-risk category. Thus, in a two step procedure, a screening questionnaire can be used to detect adolescents that are at-risk for anxiety, and high-risk adolescents can be further assessed by means of a DSM (semi-)structured interview (Essau, Muris, \& Edere, 2002; Hale, Raaijmakers, Muris, \& Meeus, 2005).

Several anxiety self-report questionnaires have been developed to evaluate anxiety disorder symptoms. In their review of anxiety rating scales, Myers and Winters (2002) concluded that the Screen for Child Anxiety Related Emotional Disorders (SCARED) is of one the best self-report instrument to evaluate anxiety symptoms.

\subsection{The Screen for Child Anxiety Related Emotional Disorders (SCARED)}

The SCARED was initially developed by Birmaher and his collaborators. It comprises of 38 -items that can be grouped into five subscales. Four of these subscales measure anxiety disorder symptoms as conceptualized in the DSM-IV-TR: panic disorder, generalized anxiety disorder, separation anxiety disorder, and social anxiety. The fifth subscale, school anxiety, represents a common anxiety problem in childhood and adolescence (Birmaher et al., 1997). 
Using the SCARED as a screen for child and adolescent anxiety symptoms has many advantages (Myers \& Winters, 2002). First, its reliability is very good. The five factors have good internal consistency, assessed by means of Cronbach's Alpha, as well as good test-retest reliability (Birmaher et al., 1997, 1999). Second, the SCARED has shown good discriminant validity, differentiating between youths with and without anxiety disorders, between individuals with specific anxiety disorders, and also between children with anxiety disorders and children with depressive disorders (Birmaher et al., 1997, 1999). Third, the convergent validity of the SCARED is good. A comparison between the SCARED and the Anxiety Disorders Interview Schedule for Children (A-DISC) found that the SCARED had strong sensitivity and specificity when compared to the A-DISC (Muris, Merckelbach, Mayer, \& Prins, 2000). Additionally, Muris, Merckelbach, Ollendick, King, and Bogie (2002) found that the SCARED is positively and meaningfully related to other anxiety questionnaires.

The SCARED was originally developed in English for a clinical population (Birmaher et al., 1997, 1999). However, translated versions have been found to be reliable instruments to assess anxiety symptoms in other countries. Specifically, Hale et al. (2005) demonstrated, by means of Confirmatory Factor Analyses (CFA), that the five-factor Dutch version of the SCARED provided a very good fit in a large Dutch community sample and it was significantly better than the one-factor solution, confirming the multidimensionality of the SCARED. Essau et al. (2002) validated the German language version of the SCARED. They found, by means of Exploratory Factor Analyses, a six-factor solution; comprising of generalized anxiety, panic, school anxiety, social anxiety, and two separation anxiety subscales. However, the internal consistency, assessed by using Cronbach's Alpha, was found to be adequate for the original SCARED subscales (generalized anxiety, panic, school anxiety, and social anxiety) and for the composite of their two separation anxiety subscales. Ogliari et al. (2006) administered the SCARED in a sample of Italian twins. By means of Exploratory Factor Analysis they only found four of the five original factors (generalized anxiety, panic, social anxiety, separation anxiety), based on a reduced number of items. The school anxiety factor was not found to be reliable. Unreliability of the school anxiety factor has been also documented in Chinese (Su, Wang, Fan, Su, \& Gao, 2008) and South African (Muris, Schmidt, Engelbrecht, \& Perold, 2002) adolescent cohorts.

\subsection{Sex and age differences in adolescent anxiety symptoms}

If it is important to examine the applicability of the SCARED in different countries, it is equally important to test the applicability of the SCARED with different groups living in the same country. In particular, the applicability of the SCARED in sex (males and females) and age (early and middle adolescents) groups deserves attention, since a wide corpus of evidence seems to indicate that anxiety symptoms varies significantly between these groups.

Previous findings on sex and age differences in adolescent anxiety are quite straightforward. In respect to sex differences, convergent evidence highlight that girls generally report higher anxiety scores than boys (Birmaher et al., 1997; Crocetti et al., in press; Essau et al., 2002; Hale et al., 2005; Muris et al., 2002a,2002b; Ogliari et al., 2006; Ollendick \& King, 1994). Regarding age differences, findings indicate that while separation anxiety disorder decreases as an adolescent grows older, other anxiety disorders increase with age (Birmaher et al., 1997; Compton, Nelson, \& March, 2000; Essau et al., 2002; Hale et al., 2005; Ogliari et al., 2006; Su et al., 2008).

\subsection{Cultural differences on anxiety symptoms}

Until now, cross-national comparisons of anxiety disorders have received little attention. As far as we know, only Muris et al. (2002b) compared the SCARED scores of two different adolescent cohorts living in different countries: South African adolescents were compared to Dutch adolescents. Findings clearly indicated that South African adolescents exhibited more anxiety symptoms that their Dutch peers. These results are in line with those documented by Opolot (1976) who found that African children from Uganda reported higher anxiety scores than their American peers. Similarly, a study in which fear content and intensity were assessed (Ollendick, Yang, King, Dong, \& Akande, 1996) revealed that Nigerian children and adolescents report higher levels of fears than their American and Australian counterparts. Therefore, differences in anxiety symptom severity between adolescents from different countries also deserves investigation.

It is for these reasons that we will explore anxiety symptom severity scores of two European countries: a southern European cohort (i.e., Italian adolescents) will be compared to a northern European one (i.e., Dutch adolescents). Existing evidence has highlighted a number of differences in the experience of adolescents from these countries. For instance, results of the Health Behavior in School-aged Children study (HBSC) of the World Health Organization (Currie et al., 2008) have indicated clear differences on levels of well-being reported by Italian and Dutch adolescents. In particular, Italian cohorts have been found to be less satisfied with their lives and also to report more health complaints than their Dutch peers. Recently, Crocetti, Schwartz, Fermani, and Meeus (2008) found that Italian adolescents, compared to a similar Dutch group, reported a more unstable identity development: they reconsidered their choices to a greater extent than their Dutch peers, showing to be uncertain about their current commitments. The authors argued that this might be due to the fact that in Italy the transition to adulthood is extended into the late twenties. Eurostat (2008) findings pointed out that, in 2006 , the employment rate of young people aged $15-24$ years was only $25 \%$ in Italy, whereas this rate was higher than $60 \%$ in the Netherlands. Similarly, the unemployment rate of individuals younger than 25 years was $21.6 \%$ in Italy and $6.6 \%$ in the Netherlands. Therefore, Italian youths enter in the labor market much later than their Dutch peers. Similarly, residential independence is achieved much later by Italian youths. Aassve, Billari, Mazzucco, and Ongaro (2002) reported that 68\% of Italian young people aged 18-34 years were living with their parents, compared to only $27 \%$ of their Dutch peers. As clearly indicated by national surveys conducted in Italy in the last two decades (for a synthesis see Buzzi, 2007), Italian young people are increasingly postponing primary life transitions. These data, taken together, suggest that Italian youths may view the adolescent period as an unstable one, during which they can experiment different alternatives, but the moment in which they will make enduring choices it is still far away. This condition, characterized by many possibilities with few certainties, may be a source of anxiety symptoms (Schwartz, 2000).

\subsection{The present study}

As previously mentioned, there is a need for tools to screen adolescents who are at-risk for anxiety disorders. In this sense, the SCARED is valid instrument to screen for adolescent anxiety (Myers \& Winters, 2002), given its adequate internal consistency, discriminant and convergent validity. However, any use of the SCARED should also take into account its applicability for different adolescent sex and age groups.

Based on this reasoning, the purpose of the present study was to validate the Italian version of the SCARED in a large community 
sample. In particular, our aim was to extend existing knowledge on the applicability of the SCARED in Italy (Ogliari et al., 2006) in several ways. First, we examined the factor structure of the SCARED by means of Confirmatory Factor Analysis (CFA). We compared a one-factor model (representing a general anxiety factor) to the theoretic five-factor model of the SCARED (Birmaher et al., 1997). After determining which models had the best fit to the data for the subgroups, we then examined sex (boys and girls) and age (early and middle adolescents) differences on anxiety scores. And finally we compared the findings of our Italian adolescent cohort to that of a Dutch adolescent cohort.

In line with the literature, we expected girls to report more anxiety than boys, and middle adolescents to exhibit higher anxiety than younger adolescents (with the exception for separation anxiety in which we expected the opposite relationship). Finally, given the relative lack of cross-national comparisons for the SCARED, we explored also differences between Italian and Dutch adolescents. In light of the differences found in general studies of well-being between adolescents of these two countries (Currie et al., 2008), we expected that the Italian adolescent cohort would report more anxiety symptoms than their Dutch peers.

\section{Method}

\subsection{Participants}

As just noted, this study compares SCARED anxiety symptom scores of Italian adolescents to Dutch adolescents. The data for the Italian sample were collected in 2006, based on the collection methodology of Hale et al. (2005) who demonstrated, by means of CFA, that the five-factor Dutch version of the SCARED provided a very good fit in a large Dutch community sample.

The Italian sample consisted of 1975 adolescents (902 boys and 1073 girls) attending various junior high and high schools in the east-central region of Italy. Participants ranged in age from 11 to 19 years $(M=14.5$; S.D. $=2.4)$. Two age groups were represented in the sample: an early adolescent group (aged 11-14 years) of 1050 adolescents $(M$ age $=12.5$ years, S.D. $=1)$ and a middle-adolescent group (aged $15-19$ years) of 925 adolescents $(M$ age $=16.8$ years, S.D. $=1.2)$.

The Dutch sample consisted of 1115 adolescents ( 520 boys and 595 girls) attending various junior high and high schools in province of Utrecht in the Netherlands. Participants ranged in age from 11 to 19 years $(M=14.2$; S.D. $=2.2)$. Two age groups were represented in the sample: an early adolescent group (aged 11-14 years) of 564 adolescents ( $M$ age $=12.3$ years, S.D. $=0.6)$ and a middle adolescent group (aged 15-19 years) of 551 adolescents $(M$ age $=16.7$ years, S.D. $=0.8)$. Both the Italian and Dutch samples consisted only of native-born Italian and Dutch adolescents. The composition of the Italian and the Dutch cohorts did not significantly differ in either sex $\left(\chi^{2}(1,3090)=0.27, n s\right)$ or age $\left(\chi^{2}(1,3090)=1.90, n s\right)$. Missing values were estimated in SPSS, using the Estimated Means (EM) procedure.

\subsection{Procedure}

Before the study, permission to administer questionnaires was obtained from the principals of the junior and high schools. Students and their parents were provided written information about the research and asked if they wished to participate. Approximately $99 \%$ of the approached students chose to participate. Research assistants visited the schools and asked adolescents to fill in the SCARED. Students who were absent on the day of testing were not assessed. Verbal instructions were given just prior to the testing to compliment the written instructions printed above each questionnaire.

\subsection{Measure}

The 38-item SCARED questionnaire (Birmaher et al., 1997) was employed in this study. The adolescent rated each symptom on a 3-point scale: 1 (almost never), 2 (sometimes), 3 (often). The subscales of the questionnaire are: panic disorder (13 items), generalized anxiety disorder (9 items), separation anxiety disorder (8 items), social anxiety (4 items), and school anxiety (4 items). Italian participants completed the Italian version of the SCARED. The Italian version of the SCARED was translated from English to Italian by a bilingual psychologist and back translated from Italian to English by another bilingual psychologist. The two English versions were then compared, with the two translators discussing and resolving discrepancies between the original and back-translated English versions. Dutch participants filled in the Dutch version of the SCARED validated by Hale et al. (2005). Cronbach's Alpha coefficients were .84 and .88 for panic, .78 and .86 for generalized anxiety, .68 and .73 for separation anxiety, .72 and .82 for social anxiety, .66 and .70 for school anxiety, and .89 and .94 for SCARED total score, in the Italian and Dutch samples, respectively.

\subsection{Data analysis}

To test the factor structure validity of the Italian version of the SCARED, both a one-factor model and a five correlated factors model were tested by means of Confirmatory Factor Analyses (CFA). For these analyses the Structural Equation Modeling program AMOS 5 was used (Arbuckle, 2003). As the data did not justify the assumption of multivariate normality, the estimation method of unweighted least squares (ULS) was employed, as was in the study by Hale et al. (2005). In order to test whether the onefactor model (representing a general anxiety factor) and the theoretic five-factor model of the SCARED were significantly different from one another we used the chi-square test. To evaluate the fit of these models we relied on various indices (Byrne, 2001): values of the Goodness of Fit Index (GFI) and the Adjusted Goodness of Fit Index (AGFI) close to 1 represents a good fit, values of the Root Mean Square Residual (RMR) and Standardized Root Mean Square Residual (SRMR) below .05 represents a good fit, and values less than .08 represents an acceptable fit. The model with the best fit to the data was then further explored as possible sex and age subgroup differences. In order to examine possible differences of anxiety scores within the Italian cohort, we performed a multivariate analysis of variance test (MANOVA) on the five anxiety symptom scores with the sex and age as independent variables.

In order to compare the Italian and the Dutch findings we employed a two-step procedure. First, we established factorial invariance of the Italian and the Dutch SCARED factor structure (Cheung \& Rensvold, 2002). To examine measurement invariance we performed a multi-group analysis in AMOS that compared two models: a model in which all the factor loadings were constrained to be equal across Italian and Dutch cohorts was compared to a model in which these factor loadings were free to vary in the two adolescent cohorts. Since in large sample sizes the delta chi-square $\left(\Delta \chi^{2}\right)$ is likely to be significant, Cheung and Rensvold (2002) recommended the use of another index, such as the delta GFI ( $\Delta \mathrm{GFI}$ ), which should be less or equal to .01 to establish invariance. We tested configural invariance (i.e., the same item were associated with the same factor in each group) and factor loadings invariance (i.e., the strength of the relation between each factor and its associated items was the same across groups)(Chen, 2007). After having established measurement invariance, we compared Italian and Dutch anxiety scores by performing a MANOVA on the five anxiety symptom scores with nationality (Italian vs. Dutch 
Table 1

Model fit indices for the one-factor model and the five-factor model of the Italian version of the SCARED.

\begin{tabular}{lrllll}
\hline & $N$ & GFI & AGFI & RMR & SRMR \\
\hline $\begin{array}{l}\text { One-factor model } \\
\text { Total sample }\end{array}$ & 1975 & .92 & .91 & .03 & .07 \\
$\quad \begin{array}{l}\text { Five-factor model } \\
\text { Total sample }\end{array}$ & 1975 & .95 & .95 & .02 & .05 \\
Boys & 902 & .95 & .94 & .02 & .06 \\
Girls & 1073 & .95 & .94 & .02 & .06 \\
Early adolescents & 1050 & .95 & .95 & .02 & .05 \\
Middle adolescents & 925 & .94 & .94 & .02 & .06 \\
\hline
\end{tabular}

Note: $N$ : number of participants; GFI: Goodness of Fit Index; AGFI: Adjusted Goodness-of-Fit Index; RMR: Root Mean Square Residual; SRMR: Standardized Root Mean Square Residual.

adolescents) as the independent variable, with sex and age as covariates.

\section{Results}

\subsection{The Italian SCARED structure}

The factor structure of the Italian version of the SCARED was examined by means of CFAs. Both the one-factor model and the five-factor model were separately tested for the overall sample and the results of these analyses were subsequently compared. Findings, reported in Table 1, demonstrated that the five-factor model had the best overall fit to the data. Furthermore, the chisquare test indicated that the five-factor model showed a significantly improved fit compared to the fit of the one-factor model $\left(\Delta \chi^{2}=506.22, \Delta d f=10, P<.001\right)$. As the five-factor model had the best fit to the data and is closely related to the theoretical assumptions of the SCARED, this model was further examined for the sex and age subgroups. Results of these separate CFAs, also reported in Table 1, indicated that the fivefactor model also had adequate fits for each subgroup. The standardized regression weights of the five correlated factors model for the entire adolescent population are reported in Table 2 .

\subsection{Sex and age differences within the Italian sample}

Results of the MANOVA indicated that, based on the Wilks' Lambda criterion, the combined dependent variables (i.e., SCARED subscale scores) were significantly affected by sex $\left(F(5,1967)=25.61, \quad P<.001, \quad \eta^{2}=.06\right)$, age $(F(5,1967)=23.43$, $\left.P<.001, \eta^{2}=.06\right)$, and sex by age interactions $(F(5,1967)=3.80$, $P<.01, \eta^{2}=.01$ ) (see Table 3 ).

\subsubsection{Sex differences}

Female adolescents were found to score significantly higher on the panic $\left(F(1,1974)=37.71, P<.001, \eta^{2}=.02\right)$, separation anxiety $\left(F(1,1974)=19.58, \quad P<.001, \quad \eta^{2}=.01\right), \quad$ generalized anxiety $\left(F(1,1974)=96.61, P<.001, \eta^{2}=.05\right)$, and social anxiety subscales $\left(F(1,1974)=5.20, P<.05, \eta^{2}=.00\right)$ than the males.

\subsubsection{Age differences}

The middle adolescent subgroup scored significantly higher on the panic $\left(F(1,1974)=6.61, P<.01, \eta^{2}=.00\right)$, generalized anxiety $\left(F(1,1974)=57.18, P<.001, \eta^{2}=.03\right)$, and school anxiety subscales $\left(F(1,1974)=15.69, P<.001, \eta^{2}=.01\right)$ than the early adolescents. On the other hand, the early adolescents scored significantly higher on separation anxiety $\left(F(1,1974)=6.90, P<.01, \eta^{2}=.00\right)$ than the middle adolescents.
Table 2

Standardized regression weights of the five-factor model for the entire Italian adolescent sample after confirmatory factor analysis.

\begin{tabular}{|c|c|c|c|c|c|}
\hline SCARED item & Panic & GAD & Separation & School & Social \\
\hline Going crazy & .62 & & & & \\
\hline Afraid without a reason & .61 & & & & \\
\hline Going to faint & .59 & & & & \\
\hline Feel weak & .60 & & & & \\
\hline Feel like I'm choking & .58 & & & & \\
\hline Afraid of a panic attack & .57 & & & & \\
\hline Things don't seem real & .55 & & & & \\
\hline Difficulty breathing & .54 & & & & \\
\hline Sweat a lot & .49 & & & & \\
\hline Going to vomit & .48 & & & & \\
\hline Feeling dizzy & .47 & & & & \\
\hline Heavy heartbeats & .45 & & & & \\
\hline Appear nervous & .43 & & & & \\
\hline I'm a worrier. & & .67 & & & \\
\hline Worry too much & & .64 & & & \\
\hline Worry if I'm liked & & .58 & & & \\
\hline Worry about the future & & .55 & & & \\
\hline Worry about the past & & .50 & & & \\
\hline Worry if something will happen & & .47 & & & \\
\hline I'm nervous & & .47 & & & \\
\hline Worry if I'm as good as others & & .41 & & & \\
\hline Worry if I do things well & & .41 & & & \\
\hline Worry about parents & & & .54 & & \\
\hline Dreams bad things will happen & & & .53 & & \\
\hline Worry about sleeping alone & & & .48 & & \\
\hline Afraid to sleep somewhere else & & & .47 & & \\
\hline Bad dreams about parents & & & .47 & & \\
\hline Afraid to be alone & & & .46 & & \\
\hline Afraid to be away from family & & & .39 & & \\
\hline Always be with parents & & & .33 & & \\
\hline Worry about going to school & & & & .73 & \\
\hline Afraid to go to school & & & & .68 & \\
\hline Head or stomachaches at school & & & & .62 & \\
\hline Don't like to go to school ${ }^{1}$ & & & & .27 & \\
\hline Difficulty talking to strangers & & & & & .72 \\
\hline Nervous with strangers & & & & & .66 \\
\hline Shy around strangers & & & & & .65 \\
\hline Dislike being with strangers & & & & & .49 \\
\hline
\end{tabular}

\subsubsection{Sex by age interactions}

Significant sex by age interactions were found for the panic $\left(F(1,1974)=8.51, \quad P<.01, \quad \eta^{2}=.00\right), \quad$ generalized anxiety $\left(F(1,1974)=7.99, P<.01, \eta^{2}=.00\right)$, and school anxiety subscales $\left(F(1,1974)=8.46, P<.01, \eta^{2}=.00\right)$. Overall, findings indicated that older female adolescents scored much higher on these anxiety subscales than younger females, whereas differences between older and younger male adolescents, albeit being in the same direction, were less pronounced.

\subsection{Cross-national comparisons}

Data of the Italian and the Dutch cohorts were pooled together in order to compare them. First of all, we established measurement invariance. The model in which the factor loadings were constrained to be equal in the Italian and Dutch groups (GFI = .95; $\mathrm{AGFI}=.95 ; \mathrm{RMR}=.02 ; \mathrm{SRMR}=.07$ ) reported a very good fit, very similar to that of the model in which the parameters were free to vary across groups $(\mathrm{GFI}=.96 ; \mathrm{AGFI}=.95 ; \mathrm{RMR}=.02 ; \mathrm{SRMR}=.06)$. Since the delta GFI was equal to one $(\Delta \mathrm{GFI}=1)$, measurement invariance was established (Cheung \& Rensvold, 2002).

Results of the MANOVA indicated that, based on the Wilks' Lambda criterion, the combined dependent variables (i.e., SCARED

\footnotetext{
1 The factor loading for this item was found to be low. We controlled whether internal consistency of this factor would increase by deleting this item. However, after deleting this item Cronbach's Alpha remained exactly the same (.66). Thus, this item was retained in the corresponding factor.
} 
Table 3

Mean scores and standard deviations (in parentheses) of the anxiety subscales.

\begin{tabular}{|c|c|c|c|c|c|c|}
\hline \multirow[t]{2}{*}{ SCARED subscales } & Males & Females & Early adolescents & Middle adolescents & \multirow[t]{2}{*}{ Italian adolescents } & \multirow[t]{2}{*}{ Dutch adolescents } \\
\hline & \multicolumn{4}{|l|}{ Italian sample } & & \\
\hline Panic & $16.85(4.05)$ & $18.03(4.38)$ & $17.19(4.08)$ & $17.83(4.46)$ & $17.49(4.27)$ & $15.77(3.72)$ \\
\hline Separation anxiety & $10.92(2.60)$ & $11.42(2.67)$ & $11.32(2.69)$ & $11.05(2.59)$ & $11.19(2.65)$ & $10.32(2.38)$ \\
\hline School anxiety & $6.29(1.87)$ & $6.20(1.85)$ & $6.08(1.83)$ & $6.43(1.88)$ & $6.24(1.86)$ & $5.05(1.50)$ \\
\hline Generalized anxiety & $15.27(3.60)$ & $16.98(3.83)$ & 15.53 (3.69) & $16.96(3.82)$ & $16.20(3.82)$ & $12.28(2.38)$ \\
\hline Social anxiety & $6.61(1.92)$ & $6.81(2.10)$ & $6.79(2.03)$ & $6.63(2.01)$ & $6.72(2.02)$ & $6.04(2.07)$ \\
\hline
\end{tabular}

Note: Significant differences are noted in bold.

subscale scores), after controlling for sex and age, were significantly affected by nationality $(F(5,3082)=201.54, \quad P<.001$, $\left.\eta^{2}=.25\right)$. Follow up univariate analyses of variance revealed significant differences between Italian and Dutch adolescents on all the anxiety subscales: panic $(F(5,3089)=126.83, P<.001$, $\left.\eta^{2}=.04\right)$, separation anxiety $\left(F(5,3089)=80.97, P<.001, \eta^{2}=.03\right)$, generalized anxiety $\left(F(5,3089)=852.21, P<.001, \eta^{2}=22\right)$, school anxiety $\left(F(5,3089)=343.95, P<.001, \eta^{2}=.10\right)$, and social anxiety $\left(F(5,3089)=78.41, P<.001, \eta^{2}=.02\right)$. Italian adolescents scored higher than their Dutch peers on all five anxiety factors (see Table 3).

\section{Discussion}

The present contribution highlights that the SCARED is a reliable instrument to assess anxiety symptoms in the general Italian adolescent population and demonstrate clear cross-national differences on anxiety levels reported by Italian and Dutch adolescents.

\subsection{The Italian version of the SCARED}

Findings of this study revealed that the Italian version of the SCARED has a clear five-factor structure, congruent with its theoretical conceptualization (Birmaher et al., 1997). Furthermore, we found that the five-factor structure of the SCARED fitted equally well to boys and girls, and to early and middle adolescents. Taken together, these findings demonstrate the robustness of the SCARED five-factor structure and provide additional evidence that this instrument is a reliable tool to assess anxiety symptoms in the Italian adolescents from the general population.

\subsection{Sex and age differences in anxiety symptoms among Italian adolescents}

Results of this study, which indicate that girls report higher anxiety scores than boys (i.e., on all anxiety subscales except for school anxiety), are consistent with an enormous corpus of evidence produced in previous studies (Birmaher et al., 1997; Crocetti et al., in press; Essau et al., 2002; Hale et al., 2005; Muris et al., 2002a,b; Ogliari et al., 2006; Ollendick \& King, 1994). Additionally, our findings demonstrate that middle adolescents exhibit higher anxiety scores (i.e., on panic, generalized anxiety, and school anxiety) than early adolescents, whereas early adolescents report more separation anxiety symptoms than middle adolescents. These findings are also in line with those reported by previous investigations (Birmaher et al., 1997; Compton et al., 2000; Essau et al., 2002; Hale et al., 2005; Ogliari et al., 2006; Su et al., 2008). Finally, results from the interaction analyses revealed that gender differences are larger in the older adolescent group, in agreement with similar findings from a recent study by Hale, Raaijmakers, Muris, Van Hoof, and Meeus (2008).

\subsection{Cross-national differences between Italian and Dutch adolescents}

This study demonstrates measurement invariance of the Italian and Dutch versions of SCARED. This means the SCARED has the same five-factor structure and the strength of the relation between each factor and its associated items is the same in the Italian and Dutch samples. After having established measurement invariance we could compare the anxiety scores of Italian and Dutch adolescents. Consistent with our hypothesis, findings reveal that Italian adolescents report much higher anxiety symptoms than their Dutch peers, after controlling for sex and age. These differences are in line with results of the Health Behaviour in School-aged Children study (HBSC) of the World Health Organization (Currie et al., 2008). This collaborative cross-national study found that Dutch adolescents are more satisfied with their lives and report less health complaints than their Italian peers. Differences between Italian and Dutch scores were large $\left(\eta^{2}=.25\right)$, with the largest difference found on generalized anxiety scores $\left(\eta^{2}=.22\right)$, followed by school anxiety scores $\left(\eta^{2}=.10\right)$. Findings from the HBSC study between Italy and the Netherlands may provide possible reasons to explain these differences in anxiety scores. Specifically, Dutch adolescents reported a better communication with their mother and father, a higher number of close friends, from whom they received higher support in dealing with school issues, and also less school pressure than Italian adolescents (Currie et al., 2008). In addition, Crocetti et al. (2008) found that Italian adolescents exhibit a more unstable identity development than their Dutch peers. These results might suggest that Italian adolescents feel less confident about their lives and their future goals. Taken together, these differences may account for variations in anxiety rates of Italian and Dutch adolescents.

\subsection{Limitations}

In terms of the limitations, we should first mention that in this study we employed solely adolescent self-reports. Although selfreport measures are essential in the collection of information of adolescent internal and subjective processes (Achenbach, McConaughy, \& Howell, 1987), multi-informant approaches, such as anxiety ratings of the adolescent by their parents and peers, could be useful in examining adolescent anxiety symptoms. Additionally, even though the SCARED has proved to be a reliable measure, selfreport findings should be used in conjunction with behavioral and diagnostic evaluations, like those obtained by means of DSM (semi-)structured interviews to determine if an adolescent actually suffers from an anxiety disorder.

Furthermore, in the Italian sample we found that differences between sex and age groups, as well as sex by age interactions, even though significant, were characterized by small effect sizes. This could be due to the fact that we presented data from a large Italian community sample. Thus, we dealt with the small differences that are found in a general population and not the more powerful differences that are obtained when comparison is made between different clinical groups (Hale et al., 2005). 
On the other hand, some large effect sizes were found when the Italian and Dutch anxiety scores were compared to one another. However, we can only advance hypotheses on the possible explanation of these differences. Therefore, future studies of the SCARED should address this issue by measuring additional constructs that could possibly explain differences in anxiety between the two countries, such as interpersonal factors that are also important for an adolescent's well-being (specifically, family and peer groups). In fact, adolescent development is strongly intertwined to interpersonal factors, such as parental and peer bonds that can provide a secure basis (Rice, 1990), necessary to experiment new roles and make personal relevant choices that may act as a buffer in the development of anxiety symptoms.

\subsection{Clinical implications}

This study demonstrated that the SCARED is a valid instrument to assess anxiety symptoms in Italian adolescents from the general community. Since the SCARED is easily administered, it can be readily employed as a screening tool for adolescents that may be at-risk for developing one or more anxiety disorders. The SCARED can be used to identify these adolescents and these adolescents can be further evaluated by completing DSM (semi-)structured interview to determine whether an anxiety disorder is indeed present and whether it causes significant distress and/or impairment (Essau et al., 2002). Adolescents who are identified as suffering from a clinically significant anxiety disorder could then be encouraged to enter a treatment program.

\subsection{Conclusion}

The findings of the present study demonstrate that the SCARED is a reliable instrument to assess anxiety symptoms in the general Italian adolescent population as well as in sex and age groups. Differences in anxiety symptoms between males and females, and early and middle adolescents are consistent with the literature. Finally, and more interestingly, clear cross-national differences stand out; Italian adolescents exhibit more anxiety symptoms than their Dutch peers.

\section{References}

Aassve, A., Billari, F., Mazzucco, F., \& Ongaro, F. (2002). Leaving home: A comparative analysis of ECHP data. Journal of European Policy, 12, 259-275.

Achenbach, T. M., McConaughy, S. H., \& Howell, C. T. (1987). Child/adolescent behavioral and emotional problems: Implications of cross-informant correlations for situational specificity. Psychological Bulletin, 101, 213-232.

American Psychiatric Association (2000). Diagnostic and statistical manual of mental disorders, fourth edition, text revision (DSM-IV-TR). Washington, DC: American Psychiatric Publishing Inc.

Arbuckle, J. L. (2003). Amos 5.0 [Computer software]. Chicago: SPSS

Bernstein, G. A., Borchardt, C. M., \& Perwien, A. R. (1996). Anxiety disorders in children and adolescents: A review of the past 10 years. Journal of the American Academy of Child and Adolescent Psychiatry, 35, 1110-1119.

Birmaher, B. Brent, D. A., Chiappetta, L. Bridge, J. Monga, S., \& Baugher, M. (1999). Psychometric properties of the Screen for Child Anxiety Related Emotional Disorders (SCARED): A replication study. Journal of the American Academy of Child and Adolescent Psychiatry, 38, 1230-1236.

Birmaher, B., Khetarpal, S., Brent, D., Cully, M., Balach, L., Kaufman, J., et al. (1997). The Screen for Child Anxiety Related Emotional Disorders (SCARED): Scale construction and psychometric characteristics. Journal of the American Academy of Child and Adolescent Psychiatry, 36, 545-553.

Byrne, B. N. (2001). Structural equation modeling with AMOS: Basic concepts, applications, and programming. Mahwah, NJ, USA: Lawrence Erlbaum Associates Publishers.

Buzzi, C. (2007). La transizione all'età adulta [The transition to adulthood]. In: C. Buzzi, A Cavalli, A. de Lillo (Eds.), Rapporto Giovani [Youths report] (pp. 33-47). Bologna: il Mulino.

Cheung, G. W., \& Rensvold, R. B. (2002). Evaluating goodness-of-fit indexes for testing measurement invariance. Structural Equation Modeling, 9, 233-255.

Chen, F. F. (2007). Sensitivity of goodness of fit indexes to lack of measurement invariance. Structural Equation Modeling, 14, 464-504.

Compton, S. N., Nelson, A. H., \& March, J. S. (2000). Social phobia and separation anxiety symptoms in community and clinical samples of children and adolescents. Journal of the American Academy of Child and Adolescent Psychiatry, 39, 1040-1046.

Crocetti, E., Klimstra, T., Keijsers, L., Hale III, W. W., \& Meeus, W. (in press). Anxiety Trajectory Classes and Identity Development in Adolescence: A Five-Wave Longitudinal Study. Journal of Youth and Adolescence, doi:10.1007/s10964-008-9302-y.

Crocetti, E., Schwartz, S., Fermani, A., Meeus, W. (2008). The Utrecht Management of Identity Commitments Scale (U-MICS): Italian Validation and Cross-National Comparisons. Submitted European Journal of Psychological Assessment.

Currie, C., Gabhainn, S. N., Godeau, E., Roberts, C., Smith, R., Currie, D., et al. (2008). Inequalities in young people's health. Health behaviour in school-aged children international report from the 2005/2006 survey. Copenhagen: World Health Organization.

Essau, C. A., Muris, P., \& Ederer, E. M. (2002). Reliability and validity of the Spence Children's Anxiety Scale and the Screen for Child Anxiety Related Emotional Disorders in German children. Journal of Behavior Therapy and Experimental Psychiatry, 33, 1-18.

Eurostat, (2008). Europe in figures - Eurostat yearbook 2008. Luxemburg: Eurostat. Available online at $<$ http://ec.europa.eu/eurostat $>$.

Hale, W. W., III, Raaijmakers, Q., Muris, P., \& Meeus, W. (2005). Psychometric properties of the Screen for Child Anxiety Related Emotional Disorders (SCARED) in the general adolescent population. Journal of the American Academy of Child and Adolescent Psychiatry, 44, 283-290.

Hale, W. W., III, Raaijmakers, Q., Muris, P., Van Hoof, A., \& Meeus, W. (2008). Developmental trajectories of adolescent anxiety disorder symptoms: A 5-year prospective community study. Journal of the American Academy of Child and Adolescent Psychiatry, 47, 556-564.

Muris, P., Merckelbach, H., Ollendick, T., King, N., \& Bogie, N. (2002a). Three traditional and three new childhood anxiety questionnaires: Their reliability and validity in a normal adolescent sample. Behaviour Research and Therapy, 40, 753-772.

Muris, P., Schmidt, H., Engelbrecht, P., \& Perold, M. (2002b). DSM-IV-defined anxiety disorder symptoms in South African children. Journal of the American Academy of Child and Adolescent Psychiatry, 41, 1360-1368.

Muris, P., Merckelbach, H., Mayer, B., \& Prins, E. (2000). How serious are common childhood fears? Behaviour Research and Therapy, 38, 217-228.

Myers, K., \& Winters, N. C. (2002). Ten-year review of rating scales. II: Scales for internalizing disorders. Journal of American Academic Child and Adolescent Psychiatry, 41, 634-659.

Ogliari, A., Citterio, A., Zanoni, A., Fagnani, C., Patriarca, V., Cirrincione, R., et al. (2006). Genetic and environmental influences on anxiety dimensions in Italian twins evaluated with the SCARED questionnaire. Journal of Anxiety Disorders, 20, 760-777.

Ollendick, T. H., \& King, N. J. (1994). Fears and their level of inference in adolescents. Behaviour Research and Therapy, 32, 635-638.

Ollendick, T. H., King, N. J., \& Muris, P. (2002). Fears and phobias in children: Phenomenology, epidemiology, and etiology. Child Adolescent Mental Health, 7, 98-106.

Ollendick, T. H., Yang, B., King, N. J., Dong, Q., \& Akande, A. (1996). Fears in American, Australian, Chinese, and Nigerian children and adolescents: A cross-cultural study. Journal of Child Psychology and Psychiatry, 37, 213-220.

Opolot, J. A. (1976). Normative data on the Children's Manifest Anxiety Scale in a developing country. Psychological Reports, 39, 587-590.

Rice, K. G. (1990). Attachment in adolescence: A narrative and meta-analytic review. Journal of Youth and Adolescence, 19(5), 511-538.

Roza, S. J., Hofstra, M. B., van der Hende, J., \& Verhulst, F. C. (2003). Stable prediction of mood and anxiety disorders based on behavioral and emotional problems in childhood: A 14-year follow-up during childhood, adolescence, and young adulthood. American Journal of Psychiatry, 160, 2116-2121.

Schwartz, B. (2000). Self-determination: The tyranny of freedom. American Psychologist, $55,79-88$.

Su, L., Wang, K., Fan, F., Su, Y., \& Gao, X. (2008). Reliability and validity of the Screen for Child Anxiety Related Emotional Disorders (SCARED) in Chinese children. Journal of Anxiety Disorders, 22, 612-621. 